This paper is available in IEEE Transactions on Industry Applications, doi 10.1109/TIA.2015.2413957 at:

URL:http://ieexplore.ieee.org/stamp/stamp.jsp?tp=\&arnumber=7061930\&isnumb er $=7159116$

Feehally, T.; Apsley, J.M., "The Doubly Fed Induction Machine as an Aero Generator," in Industry Applications, IEEE Transactions on, vol.51, no.4, pp.3462-3471, July-Aug. 2015 doi: 10.1109/TIA.2015.2413957

(C) 2015 IEEE. Personal use of this material is permitted. Permission from IEEE must be obtained for all other uses, in any current or future media, including reprinting/republishing this material for advertising or promotional purposes, creating new collective works, for resale or redistribution to servers or lists, or reuse of any copyrighted component of this work in other works. 


\title{
The Doubly-Fed Induction Machine as an Aero Generator
}

\author{
Tom Feehally, Judith Apsley \\ School of Electrical and Electronic Engineering, \\ The University of Manchester; \\ Manchester, M13 9PL, United Kingdom \\ tom.feehally@manchester.ac.uk
}

\begin{abstract}
Modern aircraft require a robust and reliable supply of electrical power to drive a growing number of high power electrical loads. Generators are driven by a mechanical offtake from the variable speed gas turbine, while a constant frequency AC network is preferred. Here doubly-fed induction machines are advantageous since they can be controlled, through a fractionally rated converter, to decouple electrical frequency from the mechanical drive speed, making control of the network frequency possible. However, the converter must be suitably rated, according to drive speed range, electrical voltage and frequency regulation, and power requirements. This paper develops and validates a simulation model of the doubly-fed induction generator system, which is applied to find the power flow through the machine's stator and rotor connections over a wide mechanical speed range in order to size the converter. A field orientated control scheme is implemented, to provide standalone voltage and frequency regulation across a drive range of $\pm 40 \%$ synchronous speed, on a purpose-built $6.6 \mathrm{~kW}$ hardware test platform. Based on the mechanical speed range of an aero gas turbine and the identified converter sizing, the suitability of a doubly-fed induction generator for aero applications is appraised. It is shown that a converter rated at $18 \%$ of full system rating can be used to meet the aircraft electrical specifications, and offer a potential improvement in aircraft performance, with no additional mechanical components.
\end{abstract}

\section{INTRODUCTION}

The electrical power demanded by modern aircraft has risen [1], in part due to the electrification of pneumatic, hydraulic and mechanical auxiliary loads [2], and also due to additional electrical components such as in-flight entertainment systems. As a result electrical power generation is now critical to aircraft operation and due to the dominance of the electrical network as a secondary power system, can directly influence the aircraft's overall efficiency and reliability.

The latest civil aircraft have a number of gas turbine (GT) driven generators with a capacity as high as $500 \mathrm{kVA}$ per engine [3]. These generators are not electrically paralleled, supplying separate distribution networks for redundancy [4]. The GT is primarily required to provide thrust, which varies according to flight stage, and so drive to the generators is variable speed over a range of approximately $2: 1$. AC electrical distribution at a constant frequency $(\mathrm{CF})$ is preferred, as this allows the size and weight of network-connected, electromagnetic components to be minimised.

The authors are grateful to the EPSRC, Rolls-Royce plc, and the University of Manchester Alumni Fund for supporting this research.
The standard method of producing $\mathrm{CF}$ AC from a variable speed drive has been to regulate drive speed using a hydraulic constant speed drive (CSD) [4] integrated with a synchronous generator. However, these systems are large (typically a similar mass to the generator [5]), have expensive maintenance requirements $[6,7]$, and low efficiency $(\eta=0.72$ for the example in [8]). Alternatively, regulation can be carried out on the electrical side, with a fully-rated converter on the output of a variable frequency generator, increasing efficiency $(n=0.77$ in [8]), but adding weight and cost [9].

Due to the drawbacks of providing $\mathrm{CF}$, variable frequency (VF) distribution has been implemented on some recent widebodied civil aircraft, simplifying the generator system to a wound-field synchronous machine, and achieving higher efficiency ( $n=0.83$ in [8]). It is suggested that VF offers a 6fold improvement in reliability over a CF, CSD fed, system [10]. The main power distribution for the Boeing 787 is specified to have a frequency range of $360 \mathrm{~Hz}$ to $720 \mathrm{~Hz}$ [3] (2:1), while for the Airbus A380 this is $370 \mathrm{~Hz}$ to $770 \mathrm{~Hz}$ [11] (2.08:1). US Military Standard 704F [12] dictates a frequency range of $360 \mathrm{~Hz}$ to $800 \mathrm{~Hz}(2.22: 1)$ for VF systems. A fixed ratio mechanical transmission exists between the generator and GT meaning that, on such a VF network, electrical frequency is directly related to the shaft speed from the GT, which itself varies with thrust. At certain stages of operation (notably taxiing and descent) thrust demand is low [13], however GT shaft speed must be kept high in order to maintain electrical frequency. This excess thrust is wasted, leading to costly brake wear when taxiing, and increased fuel consumption. This is a significant issue when fuel accounts for $28 \%$ of aircraft operating costs [14].

The doubly-fed induction generator (DFIG) offers the benefits of $\mathrm{CF}$ generation from variable speed drive, with only a fractionally rated converter and no additional mechanical components. Doubly-fed machines are more commonly associated with wind power generation [15] where constant electrical frequency generation is required from the variable drive speed of the wind turbine. The typical speed range considered is $1.86: 1,( \pm 30 \%$ of synchronous speed $)[16,17]$, narrower than the aero speed range considered here. A comparison of variable speed, $\mathrm{CF}$, solutions for wind power generation found a CSD to be approximately half the mass per $\mathrm{kW}$ of a fully rated power converter [18]. The converter rating should therefore be minimised in order for the aircraft system to benefit from advantages in efficiency and reliability. 
While wind generation DFIGs are connected to a strong, $\mathrm{CF}$, local network and can be controlled for maximum power transfer [19] (and possibly power factor correction), aircraft electrical networks are relatively weak, having a number of highly dynamic loads and only a single generator. Therefore, an aero DFIG generator must be controlled for standalone operation, to regulate network voltage and frequency [20]. The necessary self-excitation can be achieved through a DC link battery [21]. Standalone generation from a wind-driven DFIG is considered in [22], and over a wide speed range of 3:1. However the emphasis is on maximum energy capture from the wind, which follows a cubic power relationship with turbine speed, with power limiting at high speeds, whereas an aero system requires constant electrical power across the speed range. Wind power generation systems also benefit from blade pitch control which provides some drive speed regulation to the DFIG [23, 24]. Similarly, for standalone DFIG generation from a diesel engine, speed is controlled to achieve optimal efficiency [20]. This control of the prime mover is not possible for the aero system, where GT speed is determined by propulsion requirements.

A further challenge for stand-alone control is in the supply of unbalanced loading, which is to be expected as multiple single phase loads exist on an aircraft. Load unbalance results in uneven heating of windings and torque pulsations, reducing the life of the machine and connected mechanical systems [21] [25] [26]. Several control strategies have been proposed which aim to compensate for load imbalance through control of the rotor-side converter [21], 4-legged stator-side converter [25] [26] or both. Further details of the impact of unbalanced electrical loads and faults on an aircraft power network is given in [27]; active phase rebalancing is proposed to reduce stress and fatigue in mechanical systems and disturbance to the electrical network.

This paper investigates the factors determining the rating of the power converter. Given the ability of the DFIG to decouple electrical frequency from mechanical drive speed, other, nonstandard generation modes are also considered which potentially enable the simplification of electrical load design as well as enhanced GT performance. This paper extends previous theoretical studies [28, 29], and supports the simulation with a hardware implementation, identifying the system-wide benefits of the technology and sizing the necessary power converter based on simulation and hardware test results.

\section{DFIG MODELLING}

The DFIG has electrical connections to both the rotor and stator windings, and uses a rotor-side power converter with fast-acting current control, as shown in Fig. 1. The power rating of the rotor-side converter is determined by the range of slip required, and is approximately proportional to the product of stator power and slip [30].

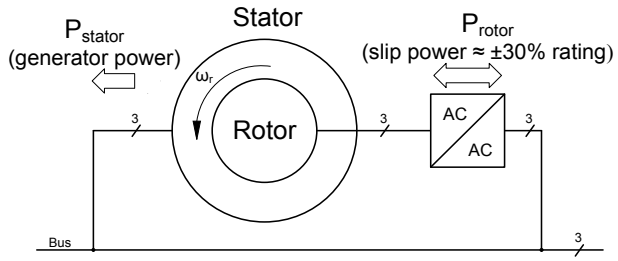

Figure 1. Doubly-fed induction generator network connections

A standard $4^{\text {th }}$ order dq-model of the induction machine core is implemented in MathWorks Simulink based on (1) and (2), from [31]. In the case of the DFIG, measurements of both rotor and stator currents are available, so the model is simulated with currents as state variables and equations are implemented in the stationary reference frame $\left(\omega_{1}=0\right)$. Clarke and Park's transforms are used to convert rotor-side variables, supplied through slip-rings to the stationary reference frame, and for implementation of the controller in the stator flux reference frame.

$$
\begin{gathered}
{\left[\begin{array}{c}
v_{s d} \\
v_{s q}
\end{array}\right]=r_{s}\left[\begin{array}{c}
i_{s d} \\
i_{s q}
\end{array}\right]+\frac{d}{d t}\left[\begin{array}{l}
\psi_{s d} \\
\psi_{s q}
\end{array}\right]+\omega_{1}\left[\begin{array}{c}
-\psi_{s q} \\
\psi_{s d}
\end{array}\right]} \\
{\left[\begin{array}{c}
v_{r d} \\
v_{r q}
\end{array}\right]=r_{r}\left[\begin{array}{c}
i_{r d} \\
i_{r q}
\end{array}\right]+\frac{d}{d t}\left[\begin{array}{l}
\psi_{r d} \\
\psi_{r q}
\end{array}\right]+\left(\omega_{1}-N_{P P} \omega_{r}\right)\left[\begin{array}{c}
-\psi_{r q} \\
\psi_{r d}
\end{array}\right]}
\end{gathered}
$$

Fluxes and currents are related by (3) and (4).

$$
\begin{aligned}
& {\left[\begin{array}{l}
\psi_{s d} \\
\psi_{s q}
\end{array}\right]=L_{s}\left[\begin{array}{l}
i_{s d} \\
i_{s q}
\end{array}\right]+L_{m}\left[\begin{array}{l}
i_{r d} \\
i_{r q}
\end{array}\right]} \\
& {\left[\begin{array}{l}
\psi_{r d} \\
\psi_{r q}
\end{array}\right]=L_{r}\left[\begin{array}{l}
i_{r d} \\
i_{r q}
\end{array}\right]+L_{m}\left[\begin{array}{l}
i_{s d} \\
i_{s q}
\end{array}\right]}
\end{aligned}
$$

Where $i, v$ and $\psi$ are current, voltage and flux respectively and subscripts denote $s$ for the stator, $r$ for the rotor, and $d$ and $q$ for dq-terms; $R_{s}$ and $R_{r}$ are the stator and rotor resistances; $L_{s}, L_{r}, L_{m}$ are the stator, rotor and magnetising resistances respectively; $\omega_{1}$ is the synchronous frequency for the arbitrary reference frame; $\omega_{r}$ is the rotor angular frequency, and $N_{p p}$ is the number of pole pairs.

A field orientated control (FOC) scheme in the stator flux reference frame, based on [32], is implemented to achieve standalone voltage $(215 \mathrm{Vrms})$ and frequency $(50 \mathrm{~Hz})$ regulation on the stator-side through the control of a rotor-side converter for a speed range of $\pm 40 \%$ around synchronous, somewhat greater than is conventionally considered for a DFIG. Fast inner loops control rotor $\mathrm{d}$ and $\mathrm{q}$ axis currents, in a similar manner to a DFIG controlled for power generation from wind [33]. The controller uses two control loops; on the q-axis a current controller maintains the necessary conditions for field alignment, and hence imposes stator frequency (5). Due to this 
alignment, the d-axis current is shown to control the stator voltage magnitude (6) where, to provide robustness to parameter variation and disturbances, an inner current control and outer voltage control loop regulate stator voltage. Standard decoupling and antiwindup techniques are used on the inner control loops $[32,33]$.

$$
\begin{aligned}
& i_{r q}{ }^{*}=-\frac{L_{s}}{L_{m}} i_{s q} \\
& \left|V_{s}\right| \approx \omega L_{m} i_{r d}
\end{aligned}
$$

Current control loops were designed for critical damping and a $1 \mathrm{kHz}$ bandwidth, which was later reduced to $500 \mathrm{~Hz}$ to improve disturbance rejection on the hardware test platform. The voltage loop was tuned using Zeigler Nichols techniques. Position information is provided by an encoder; although sensor-less control is achievable [21] [32], it is beyond the scope of this study.

\section{DFIG HARDWARE TEST PLATFORM}

To validate the model, the control scheme is implemented on the laboratory machine using a commercial converter. An aero generator test platform [34], which represents the mechanical offtake of a GT, is used to drive the DFIG and is shown in Fig. 2.

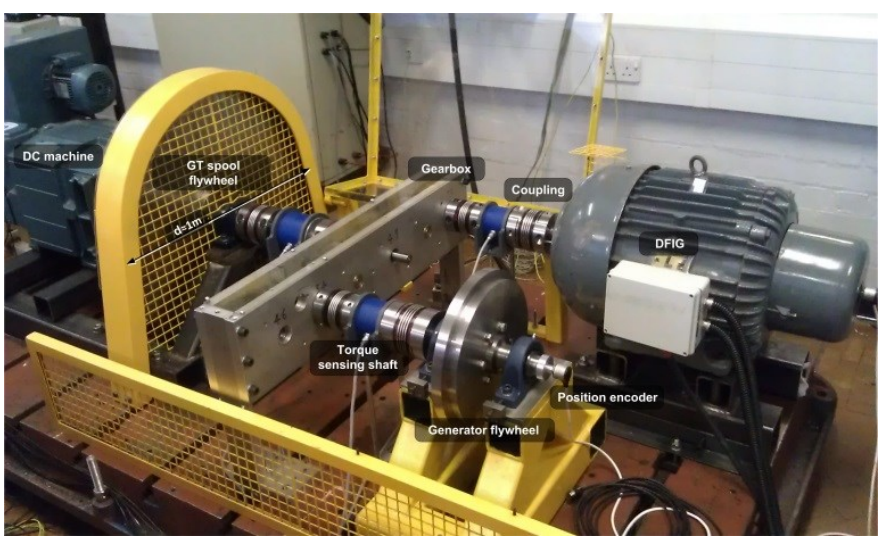

Figure 2. DFIG hardware laboratory setup

The test platform consists of a DC drive machine and flywheel which reproduce the speed and dynamics of an aero GT. A gearbox, similar to an aero accessory gearbox, transfers drive to accessory loads which in this instance are the DFIG and a flywheel representing a second generator. A commercial converter is connected to the DFIG rotor and fed from the mains supply. Loading on the DFIG stator is provided by a resistive load bank. In the test platform's present configuration, the stator-side converter is fed from the mains supply, simplifying the system dynamics in order to focus on rotor-side control and its overall rating. Interfacing the stator-side converter with the machine stator output is identified as a topic for future work.
A dSPACE controller implements the DFIG FOC scheme and gas turbine speed dynamics on the DC machine. Voltage (Testtec TT-SI9001), current (LEM LA55-P based), rotational position (Hengstler RS32-O/1024ER.11KB) and torque (NCTE Q4-200) signals throughout the test platform are recorded by a LabVIEW data acquisition system.

The test platform is scaled with power and speed for safe laboratory operation, using a commercial $6.6 \mathrm{~kW}, 50 \mathrm{~Hz}, 230 \mathrm{~V}$ rated DFIG and a speed range of 600rpm to $1,400 \mathrm{rpm}$ at the DFIG side of the gearbox. Electrical and mechanical parameters are listed in the Appendix together with rating values. Compared with the test system, an aero generator would be expected to have lower per unit core and copper losses, but higher leakage reactance. For a $400 \mathrm{~Hz}$ fundamental frequency, a current loop bandwidth above $1 \mathrm{kHz}$ would be required.

\section{A. Voltage and Current Regualtion}

The performance of the control scheme, providing standalone voltage and frequency regulation over the full drive speed range, is first appraised. The DFIG is driven at a near constant rate of acceleration, from 600rpm to $1,400 \mathrm{rpm}$, with no electrical load. Rotor current and stator voltage are shown in Fig. 3. Signals are filtered through a low-pass filter with a bandwidth of $1,000 \mathrm{~Hz}$.

Rotor frequency is near-zero at the synchronous speed of $1000 \mathrm{rpm}$, and increasing at speeds above or below this value. Voltage magnitude remains constant across the full speed range, regulated within $\pm 10 \%$. This compares with steady state voltage regulation of $5 \%$ achieved in [22], $\pm 15 \%$ described in [35] and used for a design study for aircraft VF power converters, and $\pm 5 \%$ specified in [12]. Stator frequency is calculated using a zero crossing detection algorithm and shows a regulation within $\pm 0.5 \%$ of $50 \mathrm{~Hz}$. Some of this variation must be attributed to measurement error, as the method of zero crossing detection is limited in its accuracy by the sample rate and the frequency of the measured signal.
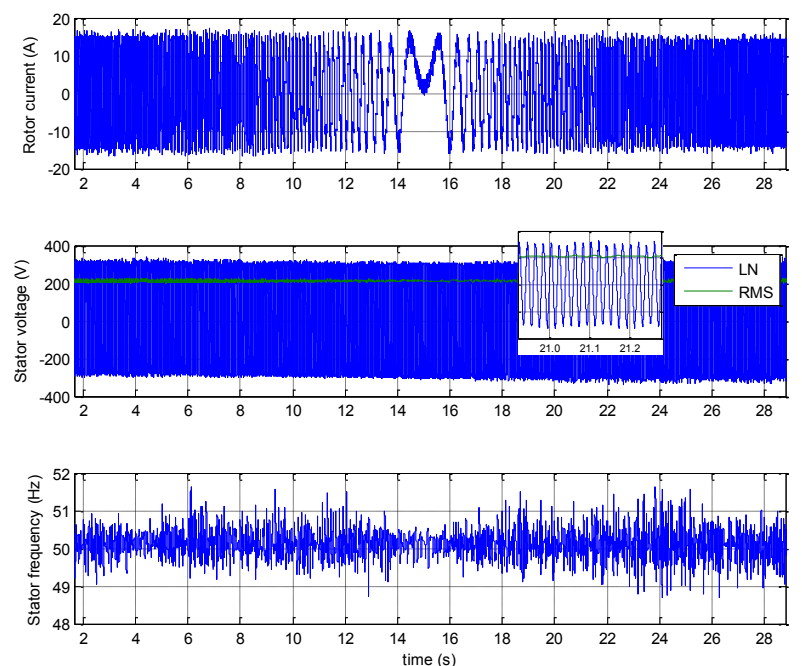

Figure 3. DFIG hardware standalone control test results - stator voltage and rotor current across full speed range with no electrical load 
To assess the control scheme during electrical load variation the DFIG is driven unloaded, and a balanced $2.7 \mathrm{~kW}$ load step is applied at 1.0s. A robust control scheme is required as the dynamics of the DFIG system vary considerably with drive speed. Results are shown for 600rpm, (-40\% slip) which represents the most challenging operating point in terms of loading on the rotor-side converter, and 900rpm in Fig. 4, and 1,100rpm and 1,400rpm in Fig. 5.
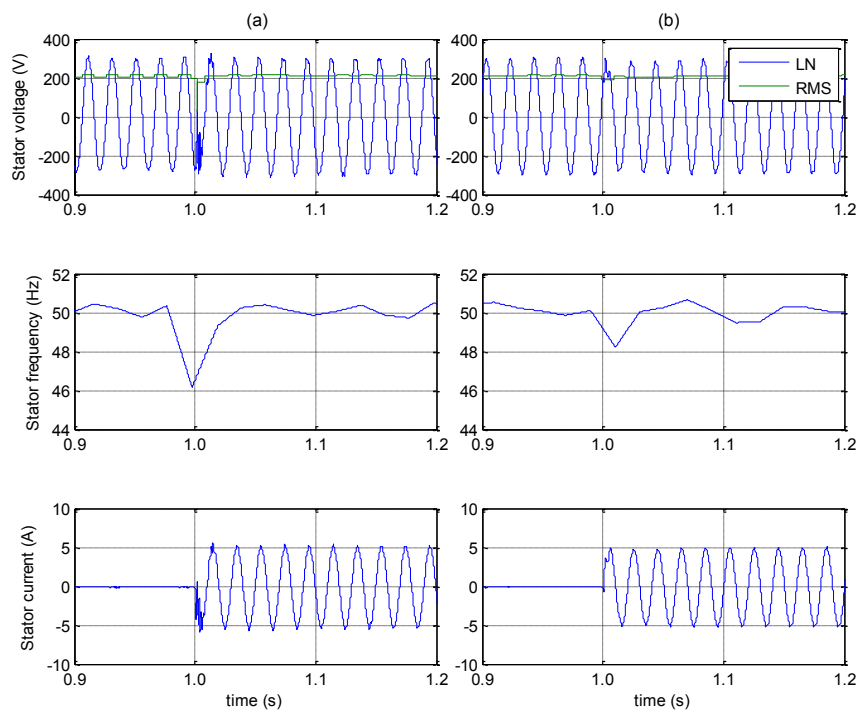

Figure 4. DFIG hardware standalone voltage regulation for $2.7 \mathrm{~kW}$ load step at (a) 600rpm and (b) $900 \mathrm{rpm}$
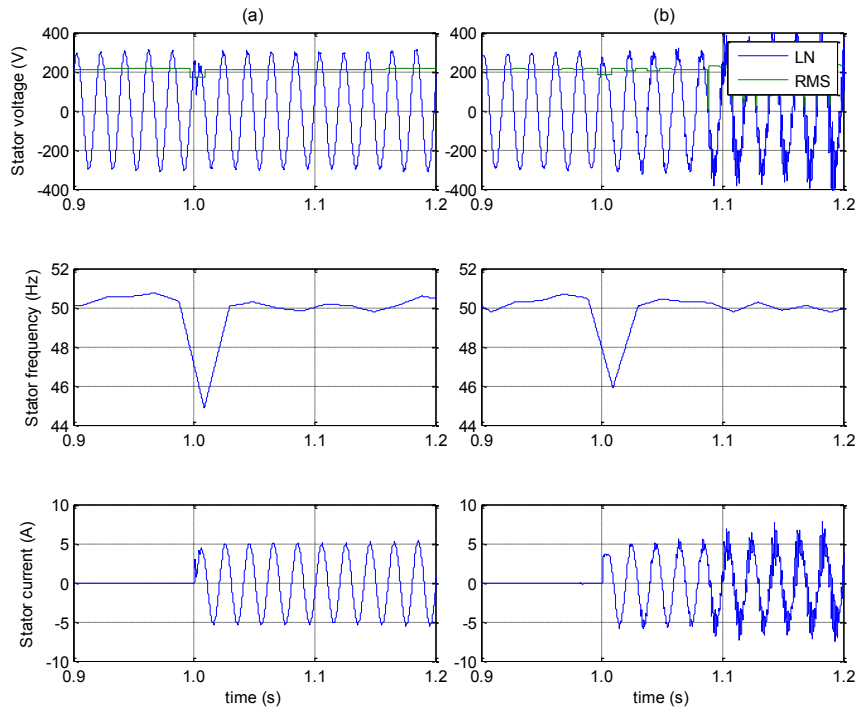

Figure 5. DFIG hardware standalone voltage regulation for $2.7 \mathrm{~kW}$ load step at (a) 1,100rpm and (b) 1,400rpm

The $2.7 \mathrm{~kW}$ load step at $1.0 \mathrm{~s}$ causes a rise in stator current, up to 3.8Arms, and a momentary drop in voltage and frequency at all drive speeds. Frequency drop is marginally lower during the transient at 1,100rpm than other drive speeds, this may be the result of variation in the point of wave when the load step is introduced. At 1,400rpm a high frequency disturbance is noted, this occurs sometime after the transient and does not remain indefinitely. This is determined to be caused by vibration from the gearbox, and is the subject of ongoing research.

The test platform's load step response is similar at both supersynchronous and subsynchronous speeds, showing good regulation across the full speed range, particularly the critical low speed condition. Stator voltage and frequency recover within $0.05 \mathrm{~s}$ at all drive speeds, showing standalone regulation that meets the transient characteristics of Military Standard 704F [12].

\section{DFIG POWER FLOW}

Three power connections exist on the DFIG, input mechanical shaft power, output electrical power from the stator, and slip power from the rotor which may act as a sink or source depending on mode of operation. The main power is generated from the stator side of the machine, connecting directly to the bus; a bidirectional converter controls frequency, and hence slip in the rotor. The rotor and stator sides are coupled to the bus so that the total output electrical bus power is the sum of the stator power and rotor slip power. At supersynchronous speeds slip power is extracted from the rotor, however at subsynchronous speeds power must be injected into the rotor to maintain the desired slip [30], and so additional stator power is required to meet this demand, as shown in Fig. 6.
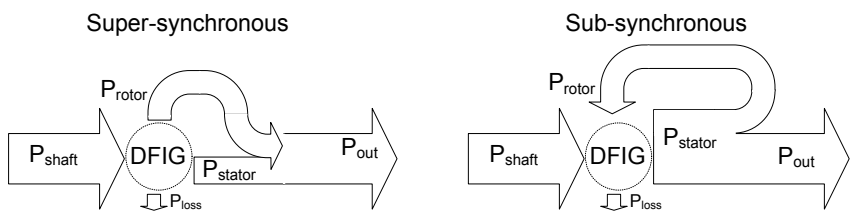

Figure 6. Doubly-fed induction generator power flow

\section{A. Simulated Power Flow}

The DFIG model with FOC scheme, from Section II, is used to identify the power levels (electrical and mechanical) in the machine across the speed range. A constant, unity power factor, electrical load $(6.6 \mathrm{~kW})$ is simulated on the bus, which must be met by the sum of the stator and rotor power from the DFIG. Fig. 7 shows the power in the rotor, stator, and shaft against drive speed. 


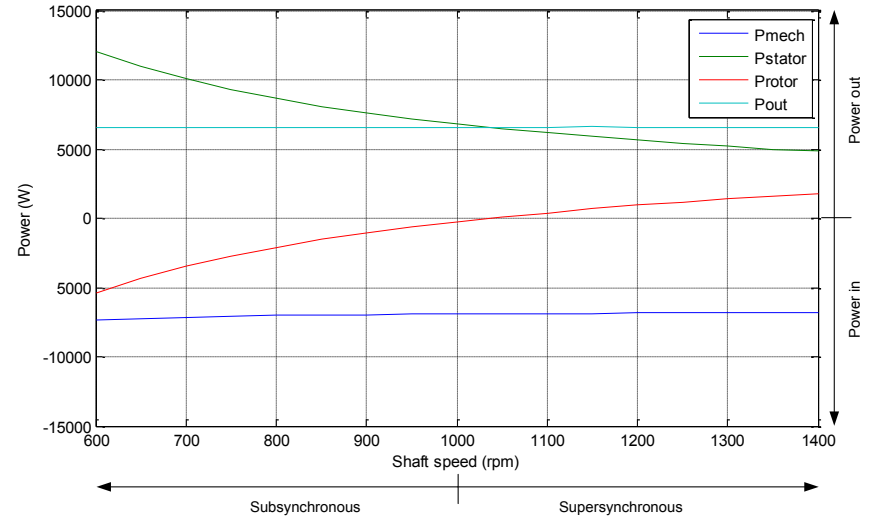

Figure 7. Modelled DFIG power across the speed range for a $6.6 \mathrm{~kW}$ load at $215 \mathrm{~V}, 50 \mathrm{~Hz}$

The simulation again shows that at subsynchronous drive speeds rotor power is injected, whilst at higher, supersynchronous speeds power is extracted from the rotor. The point at which zero real power flows in the rotor is slightly above synchronous speed, at 1,040rpm, due to resistive losses. Table I shows that because of the circulating power, the subsynchronous operating condition requires a significantly higher rating of both the rotor and the stator circuits, compared with the supersynchronous condition with the same magnitude of slip.

TABLE I. DISTRIBUTION OF RATED OUTPUT REAL POWER

\begin{tabular}{|l|c|c|c|c|c|}
\hline \multicolumn{1}{|c|}{ Drive speed (rpm) } & $\mathbf{6 0 0}$ & $\mathbf{1 0 0 0}$ & $\mathbf{1 0 4 0}$ & $\mathbf{1 4 0 0}$ & $\mathbf{1 6 0 0}$ \\
\hline \multicolumn{1}{|c|}{ Slip } & $\mathbf{- 4 0 \%}$ & $\mathbf{0}$ & $\mathbf{+ 4 \%}$ & $\mathbf{+ 4 0 \%}$ & $\mathbf{+ 6 0 \%}$ \\
\hline Stator Power (\% rating) & 182 & 103 & 100 & 73 & 64 \\
\hline Rotor Power (\% rating) & -82 & -4 & 0 & 27 & 36 \\
\hline $\begin{array}{l}\text { Combined electrical power } \\
\text { \% rating) }\end{array}$ & 264 & 107 & 100 & 100 & 100 \\
\hline $\begin{array}{l}\text { Mechanical power (\% } \\
\text { rating) }\end{array}$ & -111 & -104 & -104 & -103 & -103 \\
\hline Efficiency (\%) & 89 & 96 & 96 & 97 & 97 \\
\hline
\end{tabular}

Table I also shows the mechanical input power to the DFIG, which varies slightly with speed with the highest power at the lowest speed. Efficiency is calculated as the ratio of total electrical output power (from the rotor and the stator) to mechanical input power, and neglects converter losses and generator core and stray losses. The system efficiency is lowest at the minimum speed of $600 \mathrm{rpm}$ at $89 \%$, which corresponds to maximum circulating power and is highest at the maximum speed of $1,600 \mathrm{rpm}$ at $97 \%$, where both the rotor and stator are supplying power. At 1,040rpm, the point at which real rotor power is zero, efficiency is $96 \%$.

It is common to only consider real power, $\mathrm{P}$, however, the converter must also supply the reactive power, Q, for the machine and network, which increases its VA rating. Apparent power requirements are shown in Fig. 8 for the same, 6.6kW, electrical load given in Fig. 7.

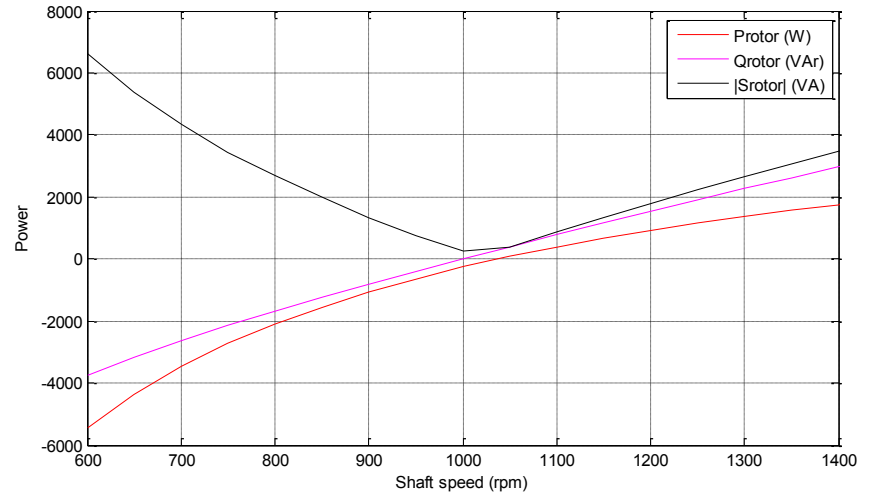

Figure 8. Modelled DFIG rotor real and reactive power flow across speed range at $6.6 \mathrm{~kW}, 215 \mathrm{~V}, 50 \mathrm{~Hz}$

Fig. 8 shows that reactive power increases with slip, with an additional increase at subsynchronous speeds, due to the higher load currents because of the re-circulating power. These values are given in Table II.

TABLE II. ROTOR REAL AND REACTIVE POWER REQUIREMENTS

\begin{tabular}{|l|c|c|c|c|c|}
\hline \multicolumn{1}{|c|}{ Drive speed (rpm) } & $\mathbf{6 0 0}$ & $\mathbf{1 0 0 0}$ & $\mathbf{1 0 4 0}$ & $\mathbf{1 4 0 0}$ & $\mathbf{1 6 0 0}$ \\
\hline \multicolumn{1}{|c|}{ Slip } & $\mathbf{- 4 0 \%}$ & $\mathbf{0}$ & $\mathbf{+ 4 \%}$ & $\mathbf{+ 4 0 \%}$ & $\mathbf{+ 6 0 \%}$ \\
\hline Real Power (kW) & -5.4 & 0 & 0 & 1.7 & 2.4 \\
\hline Reactive Power (kVAr) & -3.8 & -0.3 & 0.3 & 3.0 & 4.4 \\
\hline Apparent Power (kVA) & 6.6 & 0.3 & 0.4 & 3.5 & 5.0 \\
\hline $\begin{array}{l}\text { Apparent Power (\% } \\
\text { rating) }\end{array}$ & 100 & 3 & 6 & 53 & 76 \\
\hline
\end{tabular}

Maximum reactive power is $3.8 \mathrm{kVAr}$ at $600 \mathrm{rpm}$. Consequently, apparent power is highest at minimum speed, at $6.6 \mathrm{kVA}$, compared with $3.5 \mathrm{kVA}$ at maximum speed. It can be seen that at supersynchronous speeds, Q exceeds P, whilst at subsynchronous speeds $\mathrm{P}$ is greater than $\mathrm{Q}$.

The VA rating of the converter is considered in this paper as it provides a more accurate means of sizing the converter compared to simply considering the $\mathrm{P}$ requirements. Furthermore, as no Q is supplied mechanically, the converter acts as the sole sink/source for reactive power, which will vary according to operating speed and load power factor. A further consideration for costing the rotor-side converter is the current and voltage rating of the devices. The voltage and current magnitudes when supplying a constant, $6.6 \mathrm{~kW}$, stator load at a constant frequency are shown in Fig. 9. 


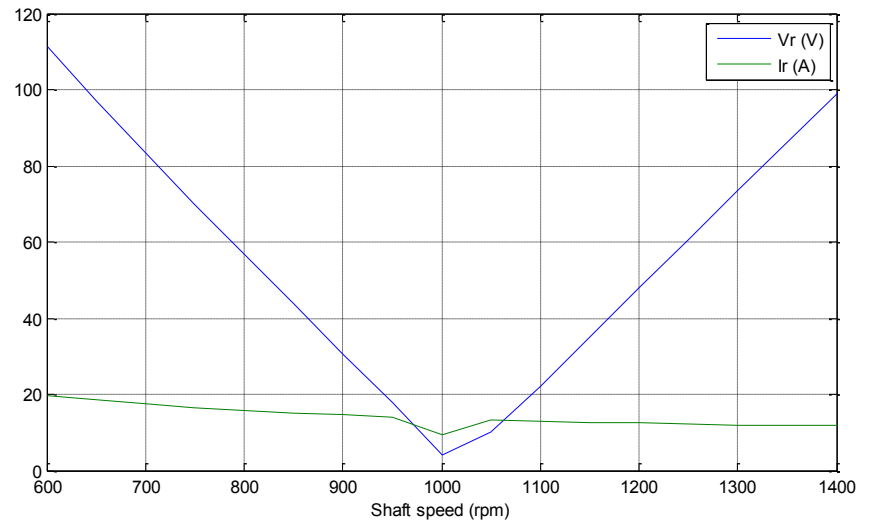

Figure 9. Modelled DFIG rotor voltage magnitude and current magnitude across speed range at $6.6 \mathrm{~kW}, 215 \mathrm{~V}, 50 \mathrm{~Hz}$

It can be seen that voltage rises approximately linearly with slip, and is higher at minimum speed than maximum speed. Current magnitude falls as speed rises as recirculated power is reduced. The power switching devices of the converter must therefore be rated for the voltage and current at the minimum speed condition, in this instance $110 \mathrm{~V}$ and $20 \mathrm{~A}$.

Unity power factor loads have so far been considered in this paper meaning that the machine magnetisation is the only requirement for Q. Aircraft load power factor is limited by Military Standard [12] and Boeing [36] to 0.85 lagging and 0.75 lagging, respectively, leading power factor loads are not permitted. Further simulation is carried out using the dynamic DFIG model to understand the impact of reactive loads on the converter rating. Fig. 10 shows the real and reactive power requirements for a constant frequency load with a worst-case power factor of 0.75 . The same apparent power load of $6.6 \mathrm{kVA}$ is considered, and so the real and reactive elements are $4.95 \mathrm{~kW}$ and $4.37 \mathrm{kVAr}$ respectively.

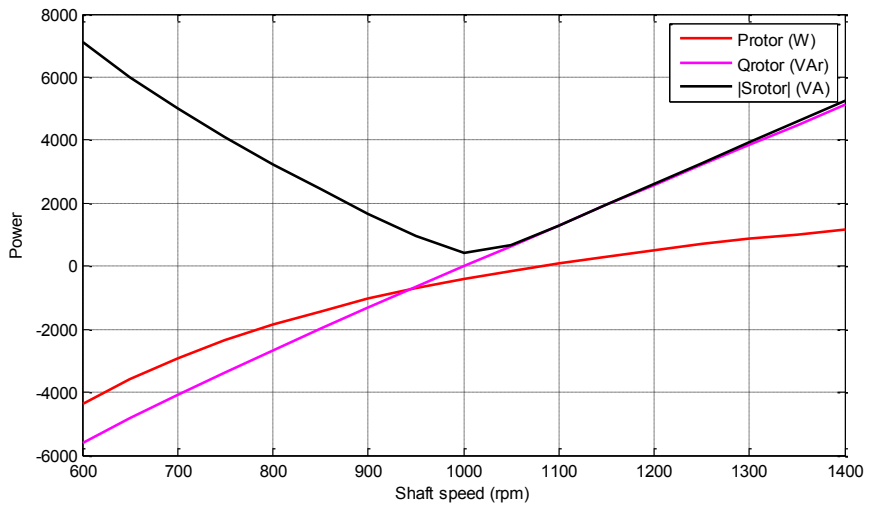

Figure 10. Modelled DFIG real and reactive power flow across speed range at 6.6kVA, $(\mathrm{pf}=0.75), 215 \mathrm{~V}, 50 \mathrm{~Hz}$

The apparent power requirement increases with slip, with an $8 \%$ higher maximum value of $7.10 \mathrm{kVA}$ at $600 \mathrm{rpm}$, compared with the unity power factor case. This is the worst case operating point, for the lowest possible power factor. Real power from the converter is lower due to the reduction in load active power; however the reactive power requirement is much higher, since the converter must now supply load reactance as well as magnetizing reactance.

\section{B. Measured Power Flow}

Measured power flow through the DFIG is shown in Fig. 11. A fully bidirectional converter is not used on the test platform; the rotor-side converter is fed from the mains supply, with reverse power being dissipated by a dump resistor, so in this instance the stator and rotor are not coupled. A $2.3 \mathrm{~kW}$ electrical load is applied and a speed range of $\pm 40 \%$ around synchronous considered. Stator and rotor powers are calculated as the sum of the products of $\mathrm{d}$ and $\mathrm{q}$ axis current and voltage, where rotor voltage is estimated from the DC link voltage and modulation index, using values from the control scheme.

Zero real power occurs in the rotor at $1,150 \mathrm{rpm}$ in the hardware compared with 1,040rpm in the simulations, which is due to the unmodelled mechanical, stray and core losses. At $600 \mathrm{rpm}$ injected rotor power is $1.03 \mathrm{~kW}$ modelled and $0.93 \mathrm{~kW}$ from the hardware and at $1,400 \mathrm{rpm}$ extracted rotor power is $0.77 \mathrm{~kW}$ modelled and $1.11 \mathrm{~kW}$ in hardware. Mechanical power is seen to be consistently higher in the hardware than simulation, indicating lower efficiency throughout the operation range, although this gap would be expected to be closer if core losses were modelled.

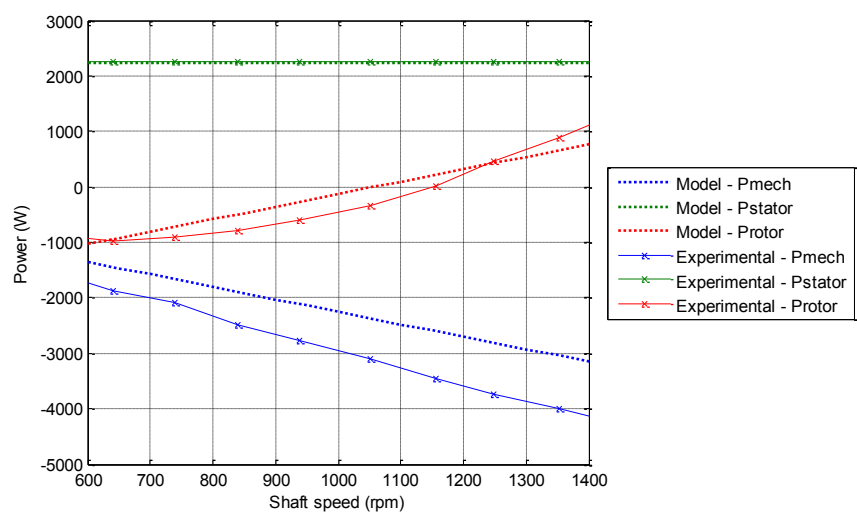

Figure 11. Modelled and hardware DFIG power flow across speed range at $2.3 \mathrm{~kW}$ load with mains fed rotor

\section{AERO GENERATOR APPLICATION}

The advantage of a DFIG system is that it permits a fractionally rated (both in terms of power and frequency) converter to deliver CF generation with a variable drive speed. However, Section IV has shown that extending the drive speed range increases the converter rating significantly in the subsynchronous mode, and that this rating is not fully utilised in the supersynchronous speed range. Since the DFIG is larger than an equivalent-rated PM generator [37], as the converter approaches full system rating the DFIG system is no longer competitive. 


\section{A. Constant frequency generation}

Based on the validated model data, which is shown in Fig. 7, to provide $\mathrm{CF} \mathrm{AC}$ for drive speed of $\pm 40 \%$ around synchronous (a speed range of 2.33:1) a converter rated at $6.6 \mathrm{kVA}(100 \%$ system rating) is required, which is set by the minimum speed and not fully utilised at maximum speed (where 93\% rating is required). Rebalancing the speed range extension, so that the converter rating is equal at both speed extremes, gives a speed range extension of $-32 \%$ to $+58 \%$ (2.33:1), requiring a converter rating of only $73 \%$ system rating. A higher synchronous speed would be achieved with a higher gear ratio between the GT and the DFIG, and require a higher speed rating for the DFIG, but no additional mechanical components.

On a typical GT, drive for the generators is extracted from the high pressure spool (intermediate pressure spool on a 3spool system) which has a speed range of approximately $2: 1$. Assuming a centred synchronous speed (minimum speed $=1$, synchronous speed $=1.5$, maximum speed $=2$ ), this is range of $\pm 33 \%$ and would require a converter rated at $76 \%$ to achieve full $\mathrm{CF}$ generation (based on data given in Fig. 7). However spool speed at cruise is around 1.3 times minimum speed. Gearing synchronous speed towards this and rebalancing the speed range extension gives a DFIG drive range of $-27 \%$ to $+45 \%$ which, for a $\mathrm{CF}$ system, requires a converter rating of $59 \%$. These configurations are illustrated in Fig. 13(a).

As the engine is at cruise speeds for the majority of its operation this assumes that the DFIG will be operated around synchronous speed for the most significant portion of operating time. From Table I, this is slightly below optimum efficiency, but gives a lower converter rating, with consequent weightsaving. It is also preferable to ensure that the nominal operating point of the converter is not at the very lowest frequency as this introduces high thermal cycling in the power electronics [38].

\section{B. Frequency-limited generation}

Discussion so far has considered only a CF mode of operation due to the system benefits over a VF network, however an alternative mode is achievable which provides variable, but limited, frequency network. This mode is shown in Fig. 12. For the variable frequency mode, electrical frequency varies linearly with GT speed. Frequency-limited operation may be achieved by capping the frequency at the low and/or high speed ranges or operating continuously to reduce the rate of change of frequency with drive speed.

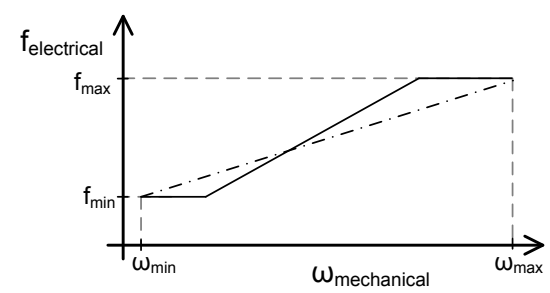

Figure 12. DFIG frequency-limited generation mode (solid line: frequency capping, dashed line: continuous scaling)
Section IV showed that converter rating increases with slip, so the rating will increase with mechanical drive speed range and reduce with electrical frequency range. Therefore a frequency-limited system will require a lower rated converter than a CF system operating over the same drive speed range. Two system benefits can be considered from the frequencylimited mode: electrical frequency range can be narrowed, reducing size/weight of electrical loads, or mechanical speed range can be extended, removing a potential constraint on the GT operation, potentially reducing fuel burn. During some flight stages there may be a mismatch between the required electrical frequency and optimal drive speed produced from the GT. Propulsive power from the GT, thrust, is directly related to spool speed [39] and, through the fixed ratio transmission, generator shaft speed. Conventionally, with a synchronous generator, the specified minimum electrical frequency artificially increases the lower limit on the GT thrust. At flight stages where the thrust requirement is low such as taxiing and descent [13] the excess propulsive power is wasted. Decoupling the electrical frequency from GT spool speed, using a DFIG, and extending the spool speed range reduces this power wastage.

Frequency-limited operation, with frequency capping, maintains the electrical frequency within the specified 2:1 band while enabling drive speed to be extended beyond the range of $2: 1$; this is achieved with a converter rating determined by the slip of the speed range extension, at minimum speed. Over the normal mechanical speed range of between 1.0 and 2.0 variable frequency would be allowed, requiring minimal power from the converter. Fig. 13(b) illustrates the frequency-limited scheme allowing drive speed to be reduced below 1.0 and down to 0.8 , in this region the electrical frequency is maintained at minimum levels. This speed range extension is achieved with only an $18 \%$ rated converter and requires no further mechanical components.

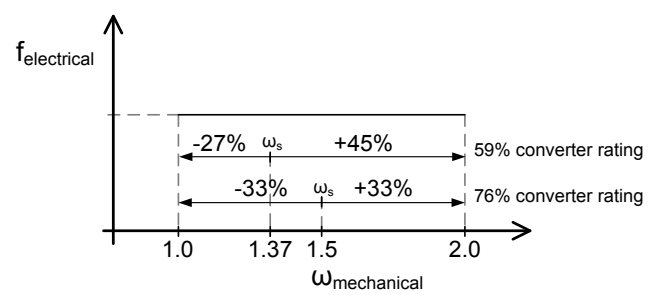

(a) Constant frequency

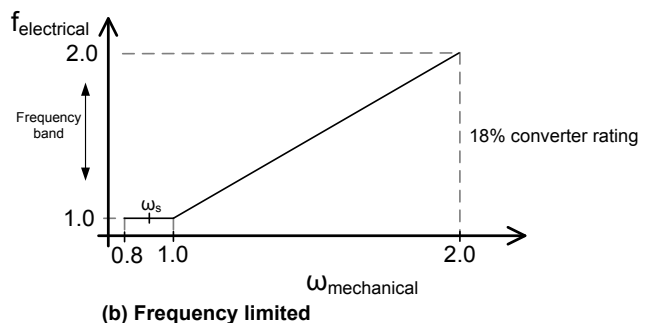

Figure 13. 3-spool GT speed range and constant frequency and frequencylimited generation modes 


\section{Simulation of frequency-limited mode}

The validated DFIG model is configured to provide variable frequency as per the frequency-limited generation mode shown in Fig. 13(b), the power flow in the converter across the speed range, including speed extension, are shown in Fig. 14.

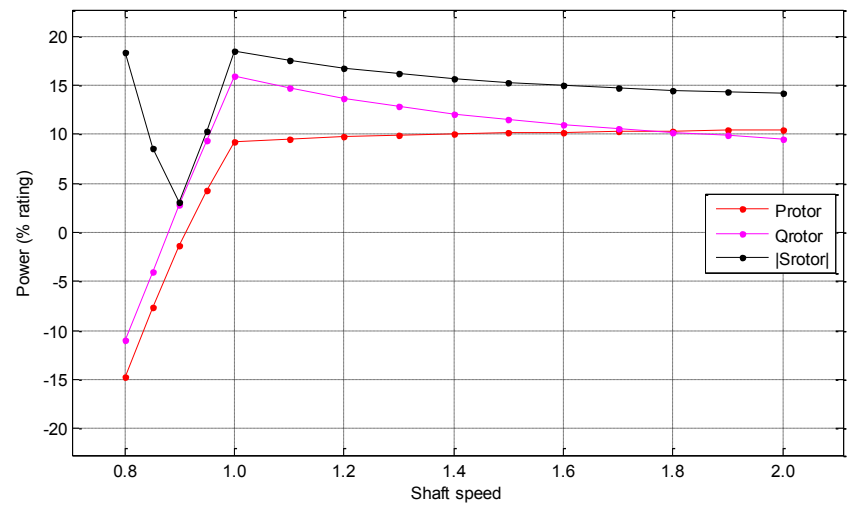

Figure 14. Modelled DFIG real and reactive power flow for frequencylimited mode

It can be seen in Fig. 14 that the converter is rated for the lowest speed where it must inject real power to maintain slip. The synchronous speed $(\approx 0.9)$ is selected so that the converter rating is utilised equally in subsynchronous and supersynchronous modes. The converter rating is not fully utilised between the speeds of 1.0 and 2.0 where the frequency is allowed to vary; this suggests that the frequency band could be narrowed further, by reduction at the top end, with the available converter rating.

The LP spool is an attractive option for electrical generation as loading at this point has the least influence on GT performance, and electrical power can be generated while windmilling. However, the LP spool range is typically much larger than the IP spool at 12:1 [3] [40] making it unsuitable for DFIG generation. Open rotor [13] [41] and turboprop systems have a narrower speed range than the turbofan GT considered in this paper, as thrust can be varied by blade pitch control, making the DFIG a more attractive option for these systems.

\section{DISCUSSION}

Generation modes and converter ratings are summarised in Table III for a unity power factor load. When delivering a CF supply over the aero mechanical speed range, a converter rating of $76 \%$ is required, this CF mode and the VF mode both have the worst case (slip and frequency) point and so converter rating is identical. The converter rating for VF is improved, to $59 \%$, when the gearing is optimised to give an asymmetric speed range extension around synchronous speed. Frequencylimited mode is able to extend the GT mechanical speed range by a factor of 1.25 to $2.5: 1$ while still requiring only an $18 \%$ rated converter.
TABLE III. GENERATING MODES AND CONVERTER RATING SUMMARY

\begin{tabular}{|c|c|c|c|}
\hline Generating mode & $\begin{array}{c}\text { Mechanical } \\
\text { speed range }\end{array}$ & $\begin{array}{c}\text { Electrical } \\
\text { frequency } \\
\text { range }\end{array}$ & $\begin{array}{c}\text { Converter rating } \\
\text { (\% system rating) }\end{array}$ \\
\hline Constant frequency & $2: 1$ & $1: 1$ & $76 \%$ \\
$( \pm 33 \%)$ & $1: 1$ & $59 \%$ \\
\hline $\begin{array}{c}\text { Constant frequency } \\
\text { (synchronous cruise } \\
\text { speed) }\end{array}$ & $\begin{array}{c}2: 1 \\
(-24 \%,+52 \%)\end{array}$ & $2: 1$ & $18 \%$ \\
\hline Frequency-limited & $2.5: 1$ & \multicolumn{2}{|c}{} \\
\hline
\end{tabular}

It should be noted that in a conventional DFIG, the connection to the rotor windings is made through slip-rings, which are less suitable for aero applications, due to their limited operational life and risk of sparking. Potential alternatives include brushless doubly-fed machines [42] and cascaded doubly-fed induction machines [43-45]. While their control is more complex, the discussions of power transfer in this paper remain largely applicable and could form the subject of further research.

\section{CONCLUSION}

In this paper the DFIG is considered as an aircraft generator. A machine model is produced and a FOC scheme implemented to provide suitable standalone voltage and frequency regulation. This system is validated against a hardware test platform up to $6.6 \mathrm{~kW}$ and used to verify power flow in the system and to size the power converter for a wide speed range, $\mathrm{CF}$, system. The real and reactive power requirements of the converter are discussed.

Several modes of electrical generation are identified (VF, $\mathrm{CF}$, frequency-limited) for an aero application, and converter sizing discussed in each case. These schemes are matched to the dynamic behaviour of an aero GT and optimised to provide maximum performance for minimal converter rating. This work demonstrates how a DFIG can meet the requirements of supplying an aero electrical network and gives numerical values for the required power converter.

It is shown that a CF network can be provided across a 2:1 aero mechanical speed range with a converter rated at 59\% system rating, providing the benefit to electrical load design with a low rated converter.

If a VF network is considered for the specified range of $2: 1$, it is shown that the mechanical speed range of the GT can be extended beyond that to $2.5: 1$, requiring a converter rated at only $18 \%$ of system rating. This potentially improves the performance of the GT in exchange for minimal additional electrical systems components.

\section{APPENDIX}

\section{A. Doubly-fed induction machine parameters}

1) Machine description:

Voltage: $415 \mathrm{~V}_{\mathrm{LL}}$, current: $20 \mathrm{~A}$ rated, power: $6.6 \mathrm{~kW}$ to stay within $20 \mathrm{~A}$ over slip range, 3-phase star connected (no neutral point access), pole pairs: 3 , slip at rated power: 0.03 .

2) Electrical and mechanical parameters 
The machine is electrically characterised according to IEEE Standard 112 [46] at ambient temperature, and with a $50 \mathrm{~Hz}$ supply, and by a number of mechanical tests. Electrical and mechanical parameters are given in Table IV.

TABLE IV. MACHINE PARAMETERS

\begin{tabular}{|l|l|}
\hline \multicolumn{1}{|c|}{ Parameter } & \multicolumn{1}{c|}{ Value } \\
\hline R1 & $0.30 \Omega$ \\
\hline R'2 & $0.45 \Omega$ \\
\hline x1 & $1.13 \Omega$ \\
\hline x'2 & $1.25 \Omega$ \\
\hline Rm & $250 \Omega$ \\
\hline xm & $25.8 \Omega$ \\
\hline Shaft inertia & $0.475 \mathrm{~kg} \cdot \mathrm{m}^{2}$ \\
\hline Bearing damping & $0.035 \mathrm{Nm} . \mathrm{rad}^{-1}$ \\
\hline
\end{tabular}

\section{ACKNOWLEDGMENT}

The authors wish to express their gratitude to P. Shaw for his contribution to the development of the aero generator test platform.

\section{REFERENCES}

[1] C. R. Avery, S. G. Burrow, and P. H. Mellor, "Electrical generation and distribution for the more electric aircraft," in 42nd International Universities Power Engineering Conference, Brighton, UK, 2007, pp. 1007-1012.

[2] C. Wenping, B. C. Mecrow, G. J. Atkinson, J. W. Bennett, and D. J. Atkinson, "Overview of Electric Motor Technologies Used for More Electric Aircraft (MEA)," Industrial Electronics, IEEE Transactions on, vol. 59, no. 9, pp. 3523-3531, 2012.

[3] A. Boglietti, A. Cavagnino, A. Tenconi, and S. Vaschetto, "The safety critical electric machines and drives in the more electric aircraft: A survey," in Annual Conference of IEEE Industrial Electronics Society, 35th (IECON '09), Porto, 2009, pp. 2587-2594.

[4] I. Moir, and A. G. Seabridge, Aircraft systems : mechanical, electrical, and avionics subsystems integration, 3rd ed., Chichester: John Wiley \& Sons, 2007.

[5] D. J. Hucker, "A Method of Weight Analysis for Constant Frequency Aircraft Electrical Generating System Equipment," Aerospace and Electronic Systems, IEEE Transactions on, vol. AES-2, no. 4-Suppl, pp. 140-150, 1966.

[6] R. Abdel-Fadil, A. Eid, and M. Abdel-Salam, "Electrical Distribution Power Systems of Modern Civil Aircrafts," in International Conference on Energy Systems and Technologies, 2nd (ICEST'13), Cairo, Egypt, 2013.

[7] F. Khatounian, E. Monmasson, F. Berthereau, and J. P. Louis, "Design of an output LC filter for a doubly fed induction generator supplying non-linear loads for aircraft applications," in IEEE International Symposium on Industrial Electronics (ISIE'04), Ajaccio, 2004, pp. $1093-$ 1098 vol. 2.

[8] D. Scholz, R. Seresinhe, I. Staack, and C. Lawson, "Fuel consumption due to shaft power off-takes from the engine," in Workshop on Aircraft System Technologies (AST 2013), Hamburg, 2013, pp. 11.
[9] I. Alan, and T. A. Lipo, "Starter/generator employing resonantconverter-fed induction machine. I. Analysis," Aerospace and Electronic Systems, IEEE Transactions on, vol. 36, no. 4, pp. 1309-1328, 2000.

[10] I. Moir, "The all-electric aircraft-major challenges," in All Electric Aircraft (Digest No. 1998/260), IEE Colloquium on, 1998, pp. 2/1-2/6.

[11] G. W. M. Norris, Airbus A380 : superjumbo of the 21st century, St. Paul, MN: Zenith Press, 2005.

[12] "Aircraft electric power characteristics (MIL-STD-704F)," Department of Defense, United States of America, 2004.

[13] A. McLoughlin, "Engine Powerplant Electrical Systems," in More Electric Aircraft Forum (MOET Project Consortium), Barcelona, Spain, 2009.

[14] J. P. Fielding, Introduction to aircraft design, New York: Cambridge University Press, 1999.

[15] M. Tazil, V. Kumar, R. C. Bansal, S. Kong, Z. Y. Dong, W. Freitas, and H. D. Mathur, "Three-phase doubly fed induction generators: an overview," Electric Power Applications, IET, vol. 4, no. 2, pp. 75-89, 2010.

[16] L. Chengwu, W. Fengxiang, and T. Yong, "Design and implementation of a doubly-fed VSCF wind power control system," in International Conference on Power System Technology (PowerCon 2002), Kunming, 2002, pp. 2126-2129 vol.4.

[17] R. Todd, M. Barnes, and A. C. Smith, "Design Study of Doubly-Fed Induction Generators for a $2 \mathrm{MW}$ Wind Turbine," Wind Engineering, vol. 33, no. 5, pp. 497-507, 2009.

[18] M. Mikhaylov, I. A. Larchikov, A. V. Yurov, V. Cvetkov, and S. Stazhkov, "Hydromechanical Constant Speed Drive for Wind-Driven Generators," in 22nd International DAAAM Symposium, Vienna, Austria, 2011.

[19] H. Azaza, and A. Masmoudi, "On the dynamic and steady state performances of a vector controlled DFM drive," in IEEE International Conference on Systems, Man and Cybernetics, Hammamet, 2002, pp. 6.

[20] R. Pena, R. Cardenas, G. M. Asher, J. C. Clare, J. Rodriguez, and P. Cortes, "Vector control of a diesel-driven doubly fed induction machine for a stand-alone variable speed energy system," in Annual Conference of IEEE Industrial Electronics Society, 28th (IECON '02), Sevilla, 2002, pp. 985-990 vol.2.

[21] R. Cardenas, R. Pena, S. Alepuz, and G. Asher, "Overview of Control Systems for the Operation of DFIGs in Wind Energy Applications," Industrial Electronics, IEEE Transactions on, vol. 60, no. 7, pp. 27762798, 2013.

[22] R. Pena, J. C. Clare, and G. M. Asher, "A doubly fed induction generator using back-to-back PWM converters supplying an isolated load from a variable speed wind turbine," Electric Power Applications, IEE Proceedings, vol. 143, no. 5, pp. 380-387, 1996.

[23] G. Gail, A. D. Hansen, and T. Hartkopf, "Controller design and analysis of a variable speed wind turbine with doubly-fed induction generator," in European Wind Energy Conference and Exhibition (EWEC '06), Athens, 2006.

[24] J. Ekanayake, L. Holdsworth, and N. Jenkins, "Control of DFIG wind turbines," Power Engineer, vol. 17, no. 1, pp. 28-32, 2003.

[25] G. Carrasco, C. Silva, R. Pena, and R. Cardenas-Dobson, "Control of a Four-Leg Converter for the Operation of a DFIG Feeding Stand-Alone, 
Unbalanced Loads," Industrial Electronics, IEEE Transactions on, vol. PP, no. 99, pp. 11, 2014.

[26] M. Pattnaik, and D. Kastha, "Harmonic Compensation With ZeroSequence Load Voltage Control in a Speed-Sensorless DFIG-Based Stand-Alone VSCF Generating System," Industrial Electronics, IEEE Transactions on, vol. 60, no. 12, pp. 5506-5514, 2013.

[27] T. Feehally, G. E. Moore, and D. R. Trainer, An electromechanical arrangement, EP 2154782 B1, EuropeanPatentOffice, 2011.

[28] M. E. Elbuluk, and M. D. Kankam, "Potential starter/generator technologies for future aerospace applications," Aerospace and Electronic Systems Magazine, IEEE, vol. 12, no. 5, pp. 24-31, 1997.

[29] F. Khatounian, E. Monmasson, F. Berthereau, E. Delaleau, and J. P. Louis, "Control of a doubly fed induction generator for aircraft application," in Annual Conference of the IEEE Industrial Electronics Society, 29th (IECON '03), Roanoke, 2003, pp. 2711-2716.

[30] M. G. Simões, and F. A. Farret, Renewable energy systems : design and analysis with induction generators, Boca Raton: CRC Press, 2004.

[31] W. Leonhard, Control of Electrical Drives, 3rd ed., Berlin: Springer, 2001.

[32] B. Hopfensperger, D. J. Atkinson, and R. A. Lakin, "Stator-flux-oriented control of a doubly-fed induction machine with and without position encoder," Electric Power Applications, IEE Proceedings, vol. 147, no. 4, pp. 241-250, 2000.

[33] R. Pena, J. C. Clare, and G. M. Asher, "Doubly fed induction generator using back-to-back PWM converters and its application to variablespeed wind-energy generation," Electric Power Applications, IEE Proceedings, vol. 143, no. 3, pp. 231-241, 1996.

[34] T. Feehally, and J. Apsley, "A Test Platform to Evaluate ElectroMechanical Interaction in Aircraft Generator Systems," in More Electric Aircraft (MEA2012), Bordeaux, 2012.

[35] G. Gong, "Comparative evaluation of three-phase high-power-facxtor AC-DC converter concepts for application in future more electric aircraft," IEEE Transactions on Industrial Electronics, vol. 52, no. 3, June, 2005.

[36] E. Matheson, and K. Karimi, "Power Quality Specification Development for More Electric Airplane Architectures."

[37] E. D. Ganev, "High-Performance Electric Drives for Aerospace More Electric Architectures Part I -- Electric Machines," in IEEE Power Engineering Society General Meeting, 2007, pp. 1-8.

[38] T. Lei, M. Barnes, and A. C. Smith, "Thermal cycling evaluation for DFIG wind turbine power converter based on joint modelling," in IEEE Energy Conversion Congress and Exposition (ECCE2013), 2013, pp. 3845-3851.

[39] B. MacIsaac, and R. Langton, Gas turbine propulsion systems: Wiley, 2011.

[40] A. J. Mitcham, and N. Grum, "An integrated LP shaft generator for the more electric aircraft," in All Electric Aircraft (Digest No. 1998/260), IEE Colloquium on, 1998, pp. 9.

[41] M. Taylor, "Open Rotor Engine Design and Validation", aerosociety.com [accessed: May 2014]

[42] S. Williamson, A. C. Ferreira, and A. K. Wallace, "Generalised theory of the brushless doubly-fed machine. I. Analysis," Electric Power Applications, IEE Proceedings, vol. 144, no. 2, pp. 111-122, 1997.
[43] T. H. Ortmeyer, and W. U. Borger, "Control of Control of Cascaded Doubly Fed Machines for Generator Applications," Power Apparatus and Systems, IEEE Transactions on, vol. PAS-103, no. 9, pp. 25642571, 1984.

[44] B. Hopfensperger, D. J. Atkinson, and R. A. Lakin, "Steady state of the cascaded doubly-fed induction machine," European Transactions on Electrical Power, vol. 12, no. 6, pp. 427-437, 2002.

[45] N. Patin, E. Monmasson, and J. P. Louis, "Analysis and control of a cascaded doubly-fed induction generator," in Annual Conference of the IEEE Industrial Electronics Society, 31 st (IECON '05), 2005, pp. 6.

[46] "IEEE Standard Test Procedure for Polyphase Induction Motors and Generators," IEEE Std 112-2004 (Revision of IEEE Std 112-1996), pp. 79, 2004. 